\title{
Hospitalization Expenditure of COVID-19 Patients at the University of the Philippines-Philippine General Hospital (UP-PGH) with PhilHealth Coverage
}

\author{
Scarlett Mia S. Tabuñar, MD, MHA ${ }^{1}$ and Tamara Michelle P. Dominado, MD² \\ ${ }^{1}$ Department of Emergency Medicine, College of Medicine, Philippine General Hospital, University of the Philippines Manila \\ ${ }^{2}$ Department of Emergency Medicine, Philippine General Hospital, University of the Philippines Manila
}

\begin{abstract}
Objective. This research aimed to determine the in-patient expenditure of COVID-19 adult patient $s$ and their outof-pocket (OOP) payments at the University of the Philippines-Philippine General Hospital (UP-PGH) after the new PhilHealth case rate coverage was instituted last 15 April 2020. It also intended to present the preliminary data on the expenses incurred by COVID patients during the initial phase of the pandemic in the country.

Methods. This study was a retrospective chart review of admitted COVID-19 patients aged 19 years old and above from 15 April to 14 August 2020 at UP-PGH that availed of PhilHealth COVID-19 case rate benefits package (C19C1-C4). Data were analyzed to extract overall expenses, out-of-pocket (OOP) charges, cost centers utilization, and other hospitalization expenditure sources.
\end{abstract}

Results. Of the 691 COVID-19 patients included during the study period, $55.72 \%$ were male, mostly belonging to the $61-70$ age range with a median age of 58 . The average in-hospital stay was 14.20 days, and $76.99 \%$ were under charity services, with the moderate $(42.84 \%)$ and mild (25.33\%) pneumonia cases accounting for $68.17 \%$ of the admissions. Total hospital expenses clustered around Php51,000 to 200,000 ( USD 1,041 to 4,156), most spending between Php101,000 to 150,000 ( USD 2,078 to 3,118). The top three cost centers and expenditure sources were pharmacies, personal protective equipment (PPE) usage, and laboratory. The average OOP payment for patients less than 60 years old was higher, ranging from Php 25,899 to Php 44,428.63 (USD 538 to USD 924.44) compared to patients older than 60 (Php4,005.60 to Php 32,920.20 USD 83.35 to 684.98). The most OOP charges were for the age group 19-30, amounting to Php 44,428.63 (USD 924.44).

Conclusion. Preliminary findings of this study gave an actual representation of the expenses of COVID-19 patients, which can guide future utilization of the national health insurance during unexpected pandemics. Early price regulation of new therapeutic interventions, diagnostic tests, and medical supplies, e.g., PPEs, disinfectants, air filters, are measures that can be implemented.

Key Words: COVID-19, health insurance, out-of-pocket expenses, PhilHealth, UP-PGH

\section{INTRODUCTION}

Corresponding author: Scarlett Mia S. Tabuñar, MD, MHA Department of Emergency Medicine Philippine General Hospital

University of the Philippines Manila

Taft Avenue, Ermita, Manila 1000, Philippines

Email: sstabunar@up.edu.ph
Healthcare is not cheap, especially in times of pandemics. Medical services usually incur unpredictable out-of-pocket (OOP) expenses even for minor problems, and medical emergencies can cause a severe financial burden. Because of this, individuals will delay or refuse to seek medical attention until the illness is already far advanced and it is too late for preventive measures. ${ }^{1}$ To alleviate this, many countries developed different healthcare financing methods, most with tax-based funding, potentially eliminating the need for outof-pocket expenditure. ${ }^{2}$ The National Health Insurance Act (Republic Act 7875) was established in 1995, which brought 
about the National Health Insurance Program (NHIP), also known as Philippine Health Insurance Corporation (PHIC) or PhilHealth, intended to be social health insurance targeting universal coverage in the entire country. ${ }^{3}$

The NHIP has a system that refunds individuals on a fee-for-service up to a specified amount based on the severity of the illness, classification of hospitals, and price ceiling for different services. ${ }^{4}$ The new system has achieved its goal of universal coverage with $95 \%$ of Filipinos enrolled in the program; however, out-of-pocket payments persist in being the primary means of health care expenditure. In 2007, they still comprised $54 \%$ of medical care cost, which is way beyond what out-of-pocket spending should be for universal coverage to be achieved; that is, it should not exceed $20-30 \%$ of total expenses. ${ }^{5} \mathrm{~A}$ study on the determination of the economic burden of community-acquired pneumonia (CAP) in 2012 by Tumanan-Mendoza et al. shows that the PhilHealth case rate payments are Philippine peso (Php) 15,000 (USD 354) and PHP32,000 (USD 754) for CAP (community-acquired pneumonia)-moderate risk (MR) and CAP-high risk (HR), respectively. ${ }^{6}$ These are underpayments for the estimated cost of hospitalization for CAP-MR, which ranged from $\mathrm{Php}$ 36,153 to 113,633 (USD 852-2,678) and Php 104,544 to 249,695 (USD2,464-5,885) for CAP-HR. It is thus shown that the hospitalization expenditure due to pneumonia is markedly higher than PhilHealth coverage, which will result in inevitable OOP payment.

The issue of excessive out-of-pocket expenditure for healthcare is still not resolved until present times, and with a global pandemic, this only further magnifies the problem. Most Filipino families are one medical emergency or disaster away from poverty. This has been seen in recent times as every non-essential service has come to a standstill brought about by the various types of community quarantine implemented to stem the spread of the virus. Most people have lost their means of livelihood as most cities have shut down, and they can only turn to the government for financial aid. Fiscal resources are focused on obtaining the necessities like shelter, water, and food. If someone in the household is to get sick, PhilHealth must be efficient enough to lessen out-of-pocket expenses so that the family can still provide for themselves during the crisis. COVID-19 is a disease caused by Severe Acute Respiratory Syndrome Coronavirus 2 (SARS-COV-2). The World Health Organization (WHO) declared the outbreak as a global emergency on 30 January 2020. ${ }^{7}$ Amid the pandemic, countries have shut their borders and have implemented various responses to 'flatten the curve' such as the enhanced community quarantine (ECQ) enforced in the Philippines. The virus has not only crippled global healthcare systems but has also negatively impacted economies that might push the world into recession. Universal health care coverage is pushed to the limit due to the increasing hospitalization expenditure as the disease timeline progresses. ${ }^{8}$
In the Philippines, at the start of the pandemic, PhilHealth announced that it would be paying all the expenses of COVID-19 patients; however, starting 15 April 2020 , beneficiaries will be covered by case rate packages categories based on the severity of illness. Patients admitted before the said date will still have their hospital bills fully compensated by the insurance program. ${ }^{9}$

With the Department of Health (DOH) designating the University of the Philippines-Philippine General Hospital (UP-PGH) as a COVID-19 referral center last 20 March 2020, UP-PGH took on the responsibility of being at the forefront of the public health crisis and patients from all economic backgrounds are seen at the hospital. This study aims to determine the hospitalization expenditure of confirmed COVID-19 adult patients, with PHIC coverage, admitted from 15 April to 14 August 2020 at the UP-PGH, the in-patient spending source, and their out-of-pocket expenses after the new case rate coverage is instituted.

\section{MATERIALS AND METHODS}

The study was a retrospective chart review of admitted COVID-19 patients aged 19 years old and above for four months from 15 April to 14 August 2020 at UP-PGH, a 1500 -bed capacity tertiary hospital that serves more than 690,000 patients every year. The data were collected from the Records Section, PhilHealth Unit, and the private patients' billing section to completely validate PhilHealth coverage and actual confinement expenditure. These included medical charts admitted from the COVID charity wards and Pay floors with final ICD-10 Code Z03.8 and with additional codes Z20.8 (Description - Patient observed without confirmation or with negative test) and U07.1 (Description - COVID-19 Confirmed) that availed of PhilHealth COVID-19 in-patient benefit package C19C1-C4. ${ }^{10,11}$ The data extracted from the hospital records include: admission date, case number, age and sex of the patient, total in-hospital stay (in days), type of ward admission (charity or pay), PhilHealth COVID-19 case rate package, the total amount of hospital expenses and breakdown of hospital expenses- in terms of a cost center or other sources of expenditure. The predetermined PHIC case rates that were implemented last 15 April 2020, based on the severity of illness, were used to analyze the data gathered. The coverages were as follows: (i) Mild Pneumonia - Php 43, 997 ( USD 914.20), (ii) Moderate Pneumonia - Php 143, 267 ( USD 2,976.93), (iii) Severe Pneumonia - Php333, 519 ( USD 6,930.16) and (iv) Critical Pneumonia - Php 786,384 ( USD 16,340.20). ${ }^{9}$

All data were encoded in Microsoft Excel and analyzed using computation of frequencies, percentages, crosstabulations, and other central tendency statistics. Ethics approval was secured from UP-Manila Research Ethics Board (UPM-REB 2020-408-01) before the commencement of the study. 


\section{RESULTS}

During the 4-month patient record review, 691 confirmed COVID-19 adult patients were admitted at PGH with a median age of 58 and mean of 56.42 years, the youngest patient was 20 years of age, and the oldest was 95 . Most of the COVID-19 patients belong to 61-70 years old, comprising $25.62 \%$ of the total population, followed by the 51-60 age group at $22.43 \%$. More than half of those admitted were male (55.72\%); details of the general characteristics of COVID-19 patients are summarized in Table 1.

The average in-hospital stay of COVID-19 patients was 14.20 days or around two weeks. The shortest stay was less than a day due to an early demise of the critical COVID-19 case at the ICU; the most extended stay was 80.71 days or 11.53 weeks 2.88 months. Most admissions lasted 1-2 weeks, with a combined percentage of 65.99 for the 0-7 and 8-14 days in-hospital stay, the bulk of which belonging to the $8-14$ days at $36.47 \%$. (Table 2 ).

Table 1. Summary of General Characteristics of COVID-19 Patients (April to August 2020)

\begin{tabular}{lcc} 
& \multicolumn{2}{c}{$\mathbf{N}=691$} \\
\cline { 2 - 3 } Data & $\mathbf{n}$ & $\%$ \\
Mex & & \\
Memale & 385 & 55.72 \\
\hline Age (years) & 306 & 44.28 \\
\hline & Min & 20 \\
& Max & 95 \\
Range & Mean & 56.42 \\
$19-30$ & Median & 58 \\
$31-40$ & $\mathbf{n}$ & $\%$ \\
$41-50$ & 51 & 7.38 \\
$51-60$ & 71 & 10.27 \\
$61-70$ & 107 & 15.48 \\
$71-80$ & 155 & 22.43 \\
$81-90$ & 177 & 25.62 \\
$91-100$ & 89 & 12.88 \\
& 37 & 5.35 \\
& 4 & 0.58 \\
\hline
\end{tabular}

Table 2. Summary of Total In-Hospital Stay of COVID-19 patients (April to August 2020)

\begin{tabular}{ccc}
\hline In-Hospital Stay(Days) & Min & 0.57 \\
& Max & 80.71 \\
Mean & 14.20 \\
Range & $\mathbf{n}$ & $\%$ \\
\hline $0-7$ & 204 & 29.52 \\
$8-14$ & 252 & 36.47 \\
$15-21$ & 119 & 17.22 \\
$22-28$ & 56 & 8.10 \\
$29-35$ & 30 & 4.34 \\
$36-42$ & 17 & 2.46 \\
$43-49$ & 5 & 0.72 \\
$50-56$ & 6 & 0.87 \\
$57-63$ & 1 & 0.14 \\
$64-70$ & 0 & 0.00 \\
$>71$ & 1 & 0.14 \\
\hline
\end{tabular}

The majority of patients or $76.99 \%$ (532 out of the 691 patients) were hospitalized under charity services, and for the severity of COVID-19, based on the definition set by PhilHealth for Mild, Moderate, Severe, and Critical Pneumonia case package; most of the cases were classified as moderate $(42.84 \%)$ and mild (25.33\%) accounting for $68.167 \%$ or 471 patients of the total admissions. The severe and critical patients took up less than a third of admissions, with a total of 220 patients. (Figure 1)

As regards to the total amount of hospitalization expenses (Table 3), more than half (385) cases clustered around the Php 51,000 to 200,000 ( USD 1,041 to 4,156),

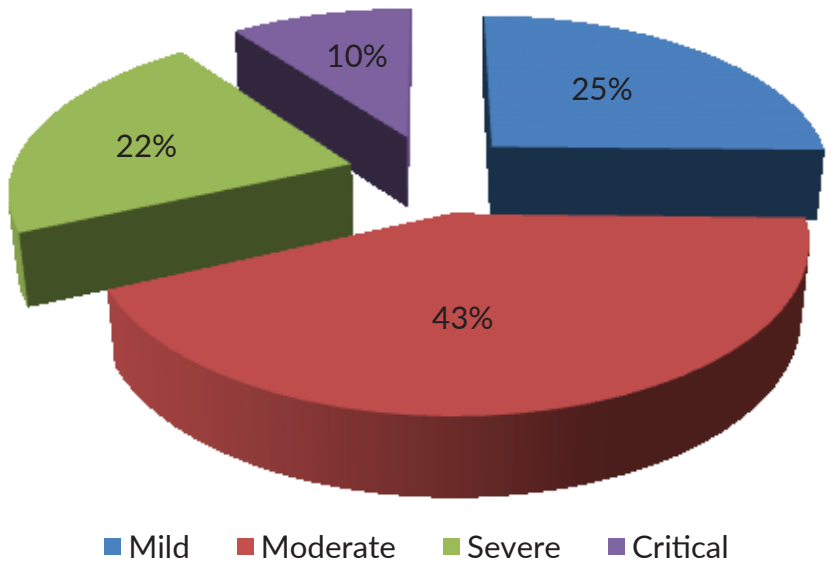

Figure 1. Distribution of COVID-19 Pneumonia Classification based on PHIC benefits.

Table 3. Summary of Total Amount of Expenses (April to August 2020)

\begin{tabular}{cccc}
\hline $\begin{array}{c}\text { Amount of Hospital } \\
\text { Expenses in Php (USD)* }\end{array}$ & $\begin{array}{c}\text { Min } \\
\text { Max } \\
\text { Rean }\end{array}$ & $\begin{array}{c}\text { 25,141.75 (USD 523.13) } \\
\text { 231,315.12 (USD 4,813.04) }\end{array}$ \\
\hline less than P50k (< USD1,040) & $\mathbf{n}$ & $\%$ \\
P51-100k (USD 1,041-2,077) & 117 & 3.47 \\
P101-150K (USD 2,078-3,118) & 149 & 21.56 \\
P151-200K (USD 3,119-4,156) & 119 & 17.22 \\
P201-250K (USD 4,157-5,195) & 52 & 7.53 \\
P251-300K (USD 5,196-6,234) & 60 & 8.68 \\
P301-350K (USD 6,235-7,273) & 42 & 6.08 \\
P351-400K (USD 7,274-8,312) & 32 & 4.63 \\
P401-450K (USD 8,313-9,351) & 26 & 3.76 \\
P451-500k (USD 9,352-10,389) & 15 & 2.17 \\
P501-550K (USD 10,390-11,428) & 14 & 2.03 \\
P551-600K (USD 11,429-12,467) & 7 & 1.01 \\
P601-650K (USD 12,468-13,506) & 7 & 1.01 \\
P651-700K (USD 13,507-14,545) & 7 & 1.01 \\
P701-750K (USD 14,546-15,584) & 6 & 0.87 \\
P751-800K (USD 15,585-16,623) & 6 & 0.87 \\
P801-850K (USD 16,624-17,662) & 0 & 0.00 \\
P851-900k (USD 17,663-18,701) & 0 & 0.00 \\
P901-950k (USD 18,702-19,740) & 0 & 0.00 \\
P951- P1M (USD 19,741-20,779) & 2 & 0.29 \\
>P1M (USD > 20,780) & 6 & 0.87 \\
\hline
\end{tabular}

${ }^{*} 1 \mathrm{USD}=48.06$ Conversion rate as of 2020 
with the greatest number of patients (149 patients or 21.56\%) spending between Php101,000 to 150,000( USD 2,078 to $3,118)$. Furthermore, the average hospital expenses was 231,315.12 (USD 4,813.04). The overall total expenditure (Table 4) for both charity and private COVID-19 patients is $160,756,150.48(\sim U S D$ 3,342,483.00), a large portion or $73.52 \%(118,186,236.95 \sim$ USD 2,457,358.75) of which was spent by charity ward admissions having 532 patients while private COVID patients accounted for $26.48 \%$ which is equivalent to Php 42,569,913.53 ( USD888,255,38).

The top three cost centers and sources of expenditure for charity patients were Pharmacy (18.06\%), personal protective equipment (PPE) usage (17.42\%) and Laboratory (16.82\%) which almost parallel that for pay patients- Laboratory (19.02\%), Pharmacy (15.01\%), PPE usage (12.99\%). The payment for doctor's professional fee accounted for the highest coverage for both patient classification at $37.81 \%$ at the charity ward and $35.66 \%$ for private ward. It is however noted that doctor's fee and room rate were fixed for charity beneficiaries based on severity of COVID infection and were not charged to patients. Largely, the laboratory, pharmacy, and PPE utilization of healthcare workers took up the largest share of the overall expenditures both for charity and pay patients at $51 \%$, with laboratories consuming the highest at Php 27,982,788 (USD 581,825.31), pharmaceuticals at Php 27,735,841.50 (USD 576,320.50), and PPEs at Php26,120,129 (USD 542,747.69). The rest of the breakdown of hospital expenses is listed in Table 4.

The average out-of-pocket (OOP) payment for patients less than 60 years old was reported to be higher, ranging from Php 25,899 to Php 44, 428.63 (USD 538- USD 924.44) compared to patients older than 60 years old (Php 4,005.60 to Php 32,920.20 USD 83.35 to 684.98). But it is, however, to be emphasized that patients older than 60 years old and PGH employees enjoy an additional 20\% and $30-50 \%$ (depending on the type of room occupied) discount with their PHIC coverage, respectively, which could explain the resulting lower OOP for senior citizens. The most OOP payment was for age group 19-30 with Php 44,428.63 (USD 924.44), and the least at ages $>91$ at only Php 4,005.60 (USD 83.35), which can also be due to it having the least number of patients afflicted with COVID-19. Data also showed that the 61-70 age range, albeit having the most significant number of admissions, did not record a higher OOP (Table 5).

The comparative monthly average expenditure (Figure 2) of COVID-19 patients were progressively growing from

Table 4. Breakdown of Hospital Expenses per Cost Center for Charity and Pay Wards

\begin{tabular}{|c|c|c|c|c|c|c|c|}
\hline \multicolumn{4}{|c|}{ Charity Ward } & \multicolumn{4}{|c|}{ Pay Ward } \\
\hline Cost center & $\begin{array}{c}\text { Average } \\
\text { Expenses } \\
\text { Php }\end{array}$ & $\begin{array}{c}\text { Total Expenses } \\
\text { Php }\end{array}$ & $\%$ & Cost center & $\begin{array}{c}\text { Average } \\
\text { Expenses } \\
\text { Php }\end{array}$ & $\begin{array}{c}\text { Total Expenses } \\
\text { Php }\end{array}$ & $\%$ \\
\hline Room type & $3,126.88$ & $1,663,500.00$ & 1.41 & Room type & $24,772.01$ & $3,938,750.00$ & 9.25 \\
\hline Doctor's Fee & $83,996.07$ & $44,685,909.00$ & 37.81 & Doctor's Fee & $94,868.77$ & $15,179,003.20$ & 35.66 \\
\hline Radiology & $3,397.28$ & $1,756,392.50$ & 1.49 & Radiology & $4,730.67$ & $742,714.50$ & 1.74 \\
\hline Laboratory & $37,375.98$ & $19,884,023.00$ & 16.82 & Laboratory & $51,606.75$ & $8,098,765.00$ & 19.02 \\
\hline Pharmacy & $40,128.01$ & $21,348,102.67$ & 18.06 & Pharmacy & $40,174.46$ & $6,387,738.83$ & 15.01 \\
\hline ECG & $2,460.00$ & $2,460.00$ & 0.002 & $\mathrm{ECG}$ & 984.75 & $132,928.00$ & 0.31 \\
\hline PPE & $38,706.77$ & $20,592,000.00$ & 17.42 & PPE & $34,988.16$ & $5,528,129.00$ & 12.99 \\
\hline Ventilator Outsource & $16,898.08$ & $2,602,304.78$ & 2.20 & Admission Kit & $1,832.61$ & $289,552.50$ & 0.68 \\
\hline Dialysis & $16,242.73$ & $1,575,545.00$ & 1.33 & Reader's fee & $2,077.45$ & $328,237.00$ & 0.77 \\
\hline Ultrasound & 207.20 & $15,540.00$ & 0.01 & Ventilator Outsource & $7,170.13$ & $329,826.00$ & 0.77 \\
\hline Radio Immunoassay Lab & 394.23 & $209,733.00$ & 0.18 & Oxygen & $12,975.44$ & $519,017.50$ & 1.22 \\
\hline 2D-Echo & $1,533.52$ & $134,950.00$ & 0.11 & Dietary & $3,535.21$ & $84,845.00$ & 0.20 \\
\hline Central ICU & $9,508.45$ & $1,074,455.00$ & 0.91 & Dialysis & $35,705.50$ & $357,055.00$ & 0.84 \\
\hline OR fee & $6,366.71$ & $108,234.00$ & 0.09 & Ultrasound & $1,289.38$ & $10,315.00$ & 0.02 \\
\hline Cobalt & $14,275.00$ & $42,825.00$ & 0.04 & Radio Immunoassay Lab & 860.71 & $24,100.00$ & 0.06 \\
\hline Ambulance Conduction & $1,422.52$ & $157,900.00$ & 0.13 & 2D-Echo & $3,348.41$ & $73,665.00$ & 0.17 \\
\hline Blood Bank & $3,298.10$ & $1,193,914.00$ & 1.01 & Central ICU & $8,221.50$ & $147,987.00$ & 0.35 \\
\hline Surgical Pathology & 186.40 & $13,980.00$ & 0.01 & Colonoscopy & $7,516.00$ & $7,516.00$ & 0.02 \\
\hline Rad Onco & $16,691.67$ & $50,075.00$ & 0.04 & OR fee & $3,406.00$ & $30,654.00$ & 0.07 \\
\hline EEG & $2,849.00$ & $28,490.00$ & 0.02 & Cobalt & $12,100.00$ & $12,100.00$ & 0.03 \\
\hline Cath Lab & $7,233.75$ & $28,935.00$ & 0.02 & Rehab & $4,400.00$ & $4,400.00$ & 0.01 \\
\hline Central Endoscopy Unit & $6,981.17$ & $83,774.00$ & 0.07 & Medical Research Lab & $6,413.93$ & $179,590.00$ & 0.42 \\
\hline Hearing Screening & $3,960.00$ & $3,960.00$ & 0.003 & Abstract & 90.00 & 90.00 & 0.0002 \\
\hline EMG & $3,015.00$ & $3,015.00$ & 0.00 & Ambulance Conduction & $2,310.00$ & $4,620.00$ & 0.01 \\
\hline MRL & $6,993.44$ & $916,140.00$ & 0.78 & Blood Bank & $19,553.13$ & $156,425.00$ & 0.37 \\
\hline MRI & $5,040.00$ & $10,080.00$ & 0.01 & Surgical Pathology & 630.00 & $1,890.00$ & 0.004 \\
\hline Total & & $\begin{array}{c}118,186,236.95 \\
S D 2,457,358.75)\end{array}$ & 73.52 & Total & & $\begin{array}{r}42,569,913.53 \\
D 888,255,38.00) \\
\end{array}$ & 26.48 \\
\hline Grand Total & & $\begin{array}{c}160,756,150.48 \\
S D 3,342,483.00)\end{array}$ & & & & & \\
\hline
\end{tabular}


Table 5. Distribution of COVID Patients per Age Group and Average OOP Payment

\begin{tabular}{ccc} 
Age & Number of Patients & Average OOP Payment, Php (USD) \\
$19-30$ & 51 & $44,428.63(924.44)$ \\
$31-40$ & 71 & $25,899.10(538.89)$ \\
$41-50$ & 107 & $35,722.13(743.28)$ \\
$51-60$ & 155 & $43,030.31(895.35)$ \\
$61-70$ & 177 & $22,484.78(467.85)$ \\
$71-80$ & 89 & $22,909.61(476.69)$ \\
$81-90$ & 37 & $32,920.20(684.98)$ \\
$>91$ & 4 & $4,005.60(83.35)$ \\
\hline Total & 691 & \\
\hline
\end{tabular}

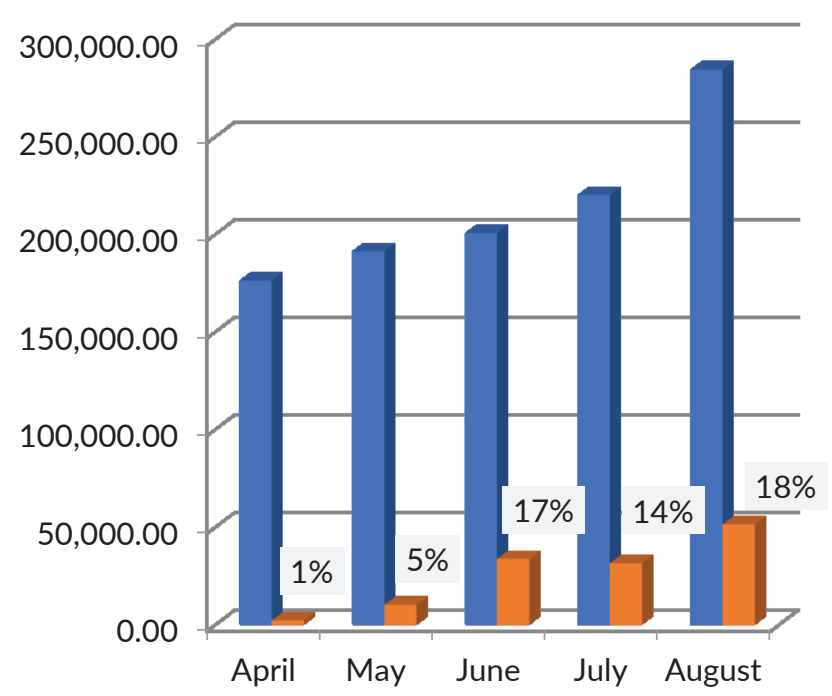

Ave. Expenditure per patient $\quad$ Ave. OOP per patient

Figure 2. Average Expenditure vs. Average OOP per patient (4-month period).

April to August with a corresponding increase in OOP, which was expectedly so due to the increasing number of patients with more severe illness coinciding with the peak of the pandemic in the country. The computed average OOP per patient for the four months was around $12 \%$ of the total hospital expenses paid. A more detailed breakdown of expenditure and OOP of patients is seen in Appendix 1.

\section{DISCUSSION}

The uncertainty of projecting the cost of COVID-19 care is a major challenge most strikingly seen at the start of the COVID-19 pandemic. In the Philippines, strict community quarantine guidelines were put in place to mitigate the spread of COVID-19, including limiting mobility, instituting minimum health standards, and restricting operations of non-essential industries to ensure health facilities will be able to cope with the potential surge of patients. In a research brief by the University of the Philippines Population Institute (UPPI), the initial identified median age of infected individuals is 50 years of age in March at the start of enhance community quarantine (ECQ). But by mid-July, the age group is noted to skew to the younger population, and the median age of COVID positives decreased to 37 years old. ${ }^{12}$ Current investigation shows that COVID-19 patients' median age is 58 , almost parallel to the median age (57) of discharged patients at the Jin Yin-Tan Hospital in Wuhan, China, during the first five months of the outbreak. ${ }^{13}$ Patients in this study are also mainly from the older age range, with the 51-60 and 61-70 having the most number combined; this may be because PGH is a COVID-19 referral center generally receiving patients that are critically ill and needing tertiary care which in all likelihood will be those who are older. More than half of those admitted are male (55.72\%), similar to the reported sex predominance in other local epidemiological studies ${ }^{14,15}$ and the weekly WHO COVID-19 Philippine situational report since April 2020. ${ }^{16}$ Vulnerable individuals were identified as minors, elderly above 60 years of age, pregnant women, and those having considerable underlying health conditions. ${ }^{17}$ According to the Centers for Disease Control and Prevention (CDC), COVID-19 hospitalization trends constantly increase 4 to 13 times higher starting from age $50{ }^{18}$ The overall health and financial burden of cases result from the overcapacity of hospitals admitting those needing medical care. Countries characterized as having high intergenerational contacts with an also high degree of residential proximity between the different age sets of family members have seen faster transmission and higher average case fatality rates (CFR), like Italy and Spain. ${ }^{19}$ In the Philippines, it is common practice to have up to 3 generations of families residing in a single housing resulting in inadvertent interactions between the susceptible and undetected asymptomatic individuals. Despite the efforts to minimize the exposure of vulnerable groups, they are mostly hospitalized. They may be exposed to their younger symptom-free household members aged 25-34 who have more robust immunity to infections and are less restricted in their mobility. ${ }^{17}$

A systematic review of the length of stay (LOS) of COVID-19 patients by Rees et al. revealed that the median hospital LOS ranged from 4 to 53 days within China and 4 to 21 days outside of China, respectively. ${ }^{20}$ In the United Kingdom, the average hospital stay is eight days shorter than the 14.20 days average in-hospital stay shown in this study. ${ }^{21}$ The shortest stay is less than a day due to the early death of the COVID-19 patient, while the longest is 80.71 days or 2.88 months. According to WHO, around $10-15 \%$ of infections progress to severe disease, while about $5 \%$ become critically ill, and the usual recovery period of the illness is after 2 to 6 weeks. ${ }^{22}$ This is very important in plotting expected hospitalization spending of a novel disease like COVID-19.

Not surprisingly, UP-PGH is the catchment center for the most serious COVID-19 cases. Moderate to critical pneumonia accounts for $75 \%$ of the hospitalizations affecting resource availability and clinical management. These types demand significant human resources allocation necessitate 
more in-patient days, and require the most, therapeuticwise. More than half of the patients spend between $\mathrm{Php}$ 51,000 to 200,000 ( USD 1,041 to 4,156), averaging at Php 231,315.12 (USD 4,813.04) with the majority shelling out between Php 101,000 to 150,000 ( USD 2,078 to 3,118). The average monthly expenditure (Figure 2 ) of patients is growing over time with a corresponding increase in OOP due to the accruing number of patients with a more severe illness that coincides with the pandemic's peaking phase in the country. The average OOP per patient during the 4-month study is around $12 \%$ of the total hospital expenses, with those aged less than 60 years paying from Php 25,899 to Php 44 428.63 (USD 538- USD 924.44), which is higher compared to those older than 60 years old ( $\mathrm{Php} \mathrm{4,005.60} \mathrm{to} \mathrm{Php}$ $32,920.20 \sim$ USD 83.35 to 684.98 ). This could also be due to the additional senior citizen discount for this age group. The 19-30 age group has the most OOP charges amounting to Php 44,428.63 (USD 924.44), and while the 61-70 age range logged the greatest number of admissions, it did not record a higher OOP payment. The top three cost centers and spending sources are pharmacy, personal protective equipment (PPE) usage, and laboratory, both for pay and charity wards. The payment for physician's professional fee has the highest coverage for both patient classification at $37.81 \%$ at the charity ward and $35.66 \%$ for the private ward; however, the doctor's fee and room rate of charity patients are not be charged to patients as they are pegged at a fixed amount contingent to the severity of COVID.

Based on the brief report of FAIR Health last July 2020, examining the private insurance claims with COVID-19 diagnoses from January to mid-May in the United States (US), the median cost for hospitalization of a COVID-19 patient is from $\$ 34,662$ for the 23-30 age group to $\$ 45,683$ for the 51-60 age group. ${ }^{23}$ In April 2020, another US private health insurance reports that the average cost to treat a hospitalized patient with the coronavirus is USD30,000. ${ }^{24}$ While in India, a 14-day treatment of an infected individual with SARs COV-2 costs between Rs2,80,000 to 3,50,000 or roughly USD 3,829 to $4,786.26$, values which approximate local spending. ${ }^{25}$ The Kaiser Family health insurance estimates an OOP cost of more than USD 1,300 for both complicated and uncomplicated COVID-19 patients with employer-based insurance. ${ }^{26}$ Steep hospital bills have been reported during the early part of the pandemic reaching up to millions of pesos ( > USD 20,000) when admitted to private hospitals in the metropolis. The major cost drivers for a typical moderate case in a private hospital are pharmaceutical products, room rates, and laboratory tests, including blood examination, $\mathrm{X}$-rays, and COVID test kits. ${ }^{27}$

Initially, factors such as the unknown course of the novel coronavirus disease, the investigational nature of the drugs used, and the individually tailored clinical pathway constituted the unregulated charges in the treatment of COVID-19 and contributed to the high OOP payments. PhilHealth implemented full coverage for all COVID-19 individuals at the beginning of the outbreak but starting 15 April 2020, coverage shifted to case severity rate packages with the intent of rationalizing benefits. But despite this adjustment, OOP payments remain high at $12 \%$ of total hospital expenditure, which is quite substantial and costprohibitive for an average Filipino. This notwithstanding the probability of more than one household member being infected and will eventually need confinement. Although the additional discounts for the senior citizens and PGH employees are not separated from the total computation of OOP payment, the total amount of hospitalization gives a fair estimate of how much it would cost for COVID confinement in general. The potential health care costs create barriers for most people from seeking and getting timely medical services, further extending the cycle of infections.

COVID requirements are different from non-COVID pneumonia. The need for PPEs, the experimental drugs, offlabel use of some medications, and the lack of standardized clinical pathway guidelines that would be needed to be the basis for PHIC coverage were not established at the initial phase of the pandemic. The present study shows that those in more advanced age generally have lesser OOP expenses despite having more comorbidities and more severe states. It can be deduced that those who have a severe or critical condition often cannot be sustained for over a week of hospitalization. That may be the reason for more negligible OOP expense or break-even coverage for its designated PHIC case package. Those with milder or moderate infections fair better but are admitted for prolonged periods, will incur higher hospital bills resulting in more OOP costs due to the disproportionate rate benefits. The younger age of the patient (less than 60 years) and the longer length of stay are factors shown to influence higher OOP charges. Little is known of this novel's actual financial cost and unfamiliar disease at the outset; it is thus understandable for PHIC estimates not to be spot-on and be based on empirical data of pre-COVID case rates for pneumonia. The gap in the actual expenditure and benefit ceilings can be attributed to the variable fee schedules of hospitalization needs like PPE, medications, investigational drugs, diagnostic workups, and interventions due to the disease's evolving course.

Several limitations have been identified in this current medical chart review. The complete data of PHIC beneficiaries were not gathered, e.g., annual household income or occupation, which could provide vital insight when quantifying the potential and actual impact of OOP spending. ${ }^{1}$ The OOP payments were calculated as the difference between total hospitalization expenditure and PHIC case rate package, which may not reflect the actual amounts spent by the patients. External expenses incurred from drugs bought from out-of-hospital pharmacies, prior confinement to other health facilities, additional COVID-19 testing, or laboratory tests before PGH admission may result in underestimating the actual cost of treatment and OOP expenses. Moreover, not all of the filed mild pneumonia cases due to 
Covid were covered because their chest $\mathrm{x}$-rays were initially not done at the outset or were missing, which should also be considered in looking at the overall expenditure picture. The turnover rates of PHIC claims for COVID cases, whether paid, returned, or denied, were only being realized now after almost a year they were filed. Lastly, as this is a secondary data review, the analysis will rely mainly on the encoded figures, which may not be standardized or comprehensive. This research only focuses on direct medical expenses brought about by the novel coronavirus, other indirect and nonmedical costs such as loss of productivity due to premature death or diminished wages, and the considerable effect on the national economy due to the lockdowns, shutting down of transportation, the closing of non-essential businesses were not explored. Thus, it is recommended for further studies to consider these factors in attempting to quantify the overall costs of this pandemic.

\section{CONCLUSION}

The coronavirus crisis further underscored the prevailing healthcare affordability problems in the country. This study's preliminary findings provide an idea of the resources necessary for COVID-19 patients by determining the average cost of hospitalization, the OOP expenses, and the different sources of expenditure. These are essential for future reference when similar outbreaks or pandemics occur as the national health insurance coverage is finite and limited. Since the COVID-19 health care cost is not mapped out in PhilHealth's annual budget, it is essential to know the needed expenses to rationalize coverage, formulate strategies to reduce OOP payment and provide better financial risk protection. This investigation will strengthen the reforms in existing policies and brief institutions about this unprecedented health scenario's economic impact. An offshoot initiative may include early price regulation of new therapeutic interventions and medical supplies, e.g., PPEs, disinfectants, air filters, etc. Hopefully, with the information gathered, policymakers and financial managers will be guided in PhilHealth's effective utilization and mitigate financial burden during unexpected pandemics.

\section{Acknowledgment}

Both authors would like to express their gratitude to UP-PGH for granting financial support to conduct this paper under the 2020 COVID Research Grant for Medical Specialist/Consultants.

\section{Statement of Authorship}

Both authors participated in data collection and analysis, and approved the final version submitted.

\section{Author Disclosure}

Both authors declared no conflicts of interest.

\section{Funding Source}

This paper was funded by the UP-PGH 2020 COVID Research Grant for Medical Specialist/Consultants.

\section{REFERENCES}

1. Tobe M, Stickley A, del Rosario Jr RB, Shibuya K. Out-of-pocket medical expenses for in-patient care among beneficiaries of the national health insurance program in the Philippines. Health Policy and Planning. 2013 August; 28(5): p. 536-48.

2. Carrin G, Mathauer I, Xu K, Evans DB. Universal coverage of health services: tailoring its implementation. Bulletin of the World Health Organization_Policy and practice. 2008 November; 86(11): p. 857-63.

3. Silfverberg. Analysis of the Philippine Health Insurance Corporation's individually paying program and employed program. Philippine Journal of Development. 2013; No.72, Vol XL: p. 1-33.

4. Obermann K, Jowett MR, Alcantara MO, Banzon EP, Bodart C. Social health insurance in a developing country: the case of the Philippines. Social Science \& Medicine. 2006 January; 62: p. 3177-85.

5. Philippine National Statistical Coordination Board. Philippine National Health Accounts.; 2010 [Internet] [cited 202019 April]. Available from: http://www.nscb.gov.ph/stats/pnha/2007/ amountexpbysource.asp\#, accessed 19 April 2020.

6. Tumanan-Mendoza A, Mendoza VL, Punzalan FER, Reganit PFM, Bacolcol SAA. Economic burden of community-acquired pneumonia among adults in the Philippines: its equity and policy implications in the case rate payments of the Philippine Health Insu..

7. World Health Organization. AWHO_News_ Joint Statement on Tourism and COVID-19 - UNWTO and WHO Call for Responsibility and Coordination. [Internet].; 2020 [cited 2020 May]. Available from: https://www.who.int/news/item/27-02-2020-a-jointstatement-on-tourism-and-covid-19---unwto-and-who-call-forresponsibility-and-coordination.

8. Nicola M, Alsafi Z, Sohrabi C, Kerwan A, Al-Jabir A, Iosifidis C, et al. The socio-economic implications of coronavirus and COVID-19 Pandemic: A Review. International Journal of Surgery. 2020 April;: p. 1-18.

9. Aguilar K. PhilHealth sets new case rate benefits for COVID-19 pateints starting 15 April. Inquirer. 202007 April.

10. Philippine Health Insurance Corporation. Guidelines on the COVID-19 Community Isolation Benefit Package (CCIBP). [Internet]. Pasig City; 2020 [cited 2020 June]. Available from: https://www.philhealth.gov.ph/covid/\#gsc.tab=0.

11. Philippine Health Insurance Corporation |. Benefit packages for inpatient care of probable and confirmed COVID-19 developing severe illness/outcomes. [Internet]. Pasig City; 2020 [cited 2020 April]. Available from: https://www.philhealth.gov.ph/covid/\#gsc.tab=0.

12. University of the Philippines Population Institute (UPPI) and Demographic Research and Development Foundation, Inc. University of the Philippines-Population Institute. [Internet].; 2020 [cited 2021 January]. Available from: https://www.uppi.upd.edu.ph/sites/ default/files/pdf/COVID-19-Research-Brief-07.pdf.

13. Huang C, Huang L, Wang Y, Li X, Ren L, Gu X, et al. 6-month consequences of COVID-19 in patients discharged from hospital: a cohort study. The Lancet. 2021 January; 397(10270): p. 220-32.

14. Haw NJL, Uy J, Sy KTL, Abrigo MRM. Epidemiological profile and transmission dynamics of COVID-19 in the Philippines. Epidemiology and Infection. 2020 September; 148(e204).

15. Salva EP, Villarama JB, Lopez EB, Sayo AR, Villanueva AMG, Edwards T, et al. Epidemiological and clinical characteristics of patients with suspected COVID-19 admitted in Metro Manila, Philippines. Tropical Medicine and Health. 2020 June; 48(56).

16. World Health Organization. Coronavirus (COVID-19) situation reports in the Philippines. Manila:; 2021.

17. Health Promotion and Communication Service, Department of Health. Healthy Pilipinas. [Internet].; 2020 [cited 2021 January]. 
Available from: https://covid19.healthypilipinas.ph/resources/ educational-materials/a-guide-to-the-new-normal.

18. Centers for Disease Control and Prevention. COVID-19 Hospitalization and Death by Age.; 2020.

19. Dowd JB, Andriano L, Brazel DM, Rotondi V, Block P, Ding X, et al. Demographic science aids in understanding the spread and fatality rates of COVID-19.; 2020.

20. Rees EM, Nightingale ES, Jafari Y, Waterlow NR, Clifford S, Pearson $\mathrm{AB}$, et al. COVID-19 length of hospital stay: a systematic review and data synthesis. BMC Medicine. 2020 September; 18(270).

21. Higham A. Coronavirus patients UK hospitals: How long do COVID-19 patients stay in hospital?.: Express; 2020 [Internet] [cited 2021 February. Available from: https://www.express.co.uk/news/ uk/1258051/Coronavirus-patients-UK-hospitals-how-long-stay-inhospital-covid-19.

22. World Health Organization. What we know about- Long-term effects of COVID-19. [Internet].; 2020 [cited 2021 February]. Available from: https://www.who.int/docs/default-source/coronaviruse/risk-commsupdates/update-36-long-term-symptoms.pdf?sfvrsn=5d3789a6_2.
23. FAIR Health. Key Characteristics of COVID-19 Patients. New York:; 2020.

24. O'Brien S. Here's what you need to know when it comes to paying for coronavirus treatment.: CNBC; 2020[Internet] [cited 2021 January]. Available from: https://www.cnbc.com/2020/04/09/heres-what-youneed-to-know-about-coronavirus-treatment-costs.html 7/8.

25. Babu R. India News. [Internet].; 2020 [cited 2021 January]. Available from: https://www.hindustantimes.com/india-news/whatdoes-it-cost-to-treat-a-coronavirus-patient-here-s-a-break-up/storyqwOzwoaJKj39AAxb2U58oO.html.

26. Abrams A. Total Cost of Her COVID-19 Treatment: \$34,927.43. [Internet].; 2020 [cited 2021 January]. Available from: https://time. com/5806312/coronavirus-treatment-cost/.

27. Punzalan J. How much to be treated for COVID-19 in Metro Manila private hospital? for moderate case, prepare at least P1M. [Internet].; 2020 [cited 2021 January]. Available from: https://www.pep.ph/ lifestyle/health-and-fitness/150720/covid-19-treatment-cost-a383020200409-1frm.

\section{APPENDIX}

Appendix 1. Summary of Expenditure \& Out-of-Pocket per Month of COVID-19 Patients (4-month period)

\begin{tabular}{|c|c|c|c|c|c|}
\hline Month & $\begin{array}{l}\text { Number of } \\
\text { Patients }\end{array}$ & $\begin{array}{l}\text { Total Expenditure of Patients, } \\
\text { Php (USD) }\end{array}$ & $\begin{array}{l}\text { Average Expenditure per } \\
\text { Patient, Php (USD) }\end{array}$ & $\begin{array}{c}\text { Total Out-of-pocket (OOP), } \\
\text { Php (USD) }\end{array}$ & $\begin{array}{l}\text { Average out-of-pocket } \\
\text { (OOP) per patient (USD) }\end{array}$ \\
\hline April & 12 & $2,139,528.85(44,517.87)$ & $178,294.07(3,709.82)$ & $26,822.40(558.10)$ & $2,235.20(46.51)$ \\
\hline May & 75 & $14,280,902.46(297,147.37)$ & $190,412.03(3,961.96)$ & $768,690.60(15,994.39)$ & $10,249.21(213.26)$ \\
\hline June & 160 & $32,100,309.11(667,921.54)$ & $200,626.93(4,174.51)$ & $5,399,130.61(112,341.46)$ & $33,744.57$ (702.13) \\
\hline July & 234 & $51,688,436.19(1,075,498.05)$ & $220,890.75(4,596.15)$ & $7,384,889.75(153,659.80)$ & $31,559.36(656.67)$ \\
\hline August & 210 & $60,552,973.87(1,259,945.36)$ & $288,347.49(5,999.74)$ & $10,790,641.09(224,524.37)$ & $51,384.01(1,069.16)$ \\
\hline Total & 691 & $160,762,150.48(3,345,030.18)$ & $232,651.45(4,840.85)$ & $24,370,174.45(507,078.12)$ & $35,267.98(733.83)$ \\
\hline
\end{tabular}

\section{The Acta Medica Philippina is now accepting} original scientific papers, review articles and case reports for its upcoming issues. Please follow the format for submission as indicated in the "Instructions to Authors" elsewhere in the journal. All papers received shall be properly acknowledged. For inquiries and submission of proposals, please email us at actamedicaphilippina.upm@up.edu.ph 